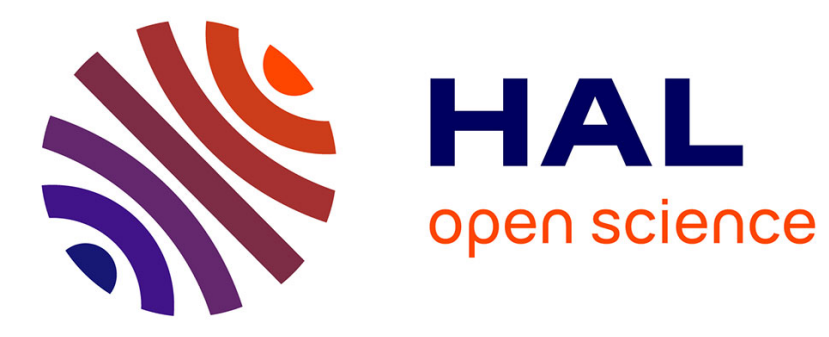

\title{
Wet spinning of a library of carbohydrate low molecular weight gels
}

Delphine Bordignon, Barbara Lonetti, Christophe Coudret, Pierre Roblin, Pierre Joseph, Laurent Malaquin, Anaïs Chalard, Juliette Fitremann

\section{- To cite this version:}

Delphine Bordignon, Barbara Lonetti, Christophe Coudret, Pierre Roblin, Pierre Joseph, et al.. Wet spinning of a library of carbohydrate low molecular weight gels. Journal of Colloid and Interface Science, 2021, 603, pp.333 - 343. 10.1016/j.jcis.2021.06.058 . hal-03278411

\section{HAL Id: hal-03278411 \\ https://hal.science/hal-03278411}

Submitted on 5 Jul 2021

HAL is a multi-disciplinary open access archive for the deposit and dissemination of scientific research documents, whether they are published or not. The documents may come from teaching and research institutions in France or abroad, or from public or private research centers.
L'archive ouverte pluridisciplinaire HAL, est destinée au dépôt et à la diffusion de documents scientifiques de niveau recherche, publiés ou non, émanant des établissements d'enseignement et de recherche français ou étrangers, des laboratoires publics ou privés. 
This document is the author version of a work published in Journal of Colloid and Interface Science, copyright (CElsevier after peer review and technical editing by the publisher. The final edited and published work is available at:

https://www.sciencedirect.com/science/article/pii/S0021979721009322

Citation: Bordignon, D.; Lonetti, B.; Coudret, C.; Roblin, P.; Joseph, P.; Malaquin, L.; Chalard, A.; Fitremann, J. Wet Spinning of a Library of Carbohydrate Low Molecular Weight Gels. Journal of Colloid and Interface Science 2021, 603, 333-343. https://doi.org/10.1016/j.jcis.2021.06.058.

\section{Wet spinning of a library of carbohydrate low molecular weight gels}

Delphine Bordignon ${ }^{\mathrm{a}}$, Barbara Lonetti ${ }^{\mathrm{a}}$, Christophe Coudret $^{\mathrm{a}}$, Pierre Roblin ${ }^{\mathrm{c}}$, Pierre Joseph ${ }^{\mathrm{b}}$, Laurent Malaquin ${ }^{\mathrm{b}}$, Anaïs Chalard ${ }^{\mathrm{a}, \#}$, Juliette Fitremann ${ }^{\mathrm{a}}$

a Laboratoire des IMRCP, Université de Toulouse, CNRS UMR 5623, Université Toulouse III - Paul Sabatier, Toulouse, France

b LAAS-CNRS, Université de Toulouse, CNRS, UPS, Toulouse, France

c Laboratoire de Génie Chimique (LGC), Université de Toulouse, CNRS UMR 5503, Université Toulouse III - Paul Sabatier, Toulouse, France

\# present address: Department of Chemical and Materials Engineering, The University of Auckland, New Zealand

Corresponding author:

Juliette Fitremann

juliette.fitremann@univ-tlse3.fr

Tel +33561556804

Laboratoire des IMRCP

Bâtiment 2R1, Université Paul Sabatier Toulouse III

118 Route de Narbonne

31062 Toulouse cedex 9

France

Authors' emails

Delphine Bordignon

cannot be published (private email address)

Barbara Lonetti lonetti@chimie.ups-tlse.fr

Christophe Coudret coudret@chimie.ups-tlse.fr

Pierre Roblin

Pierre Joseph

Laurent Malaquin

Anaïs Chalard roblin@chimie.ups-tlse.fr pierre.joseph@laas.fr laurent.malaquin@laas.fr a.chalard@auckland.ac.nz 


\section{Graphical Abstract}

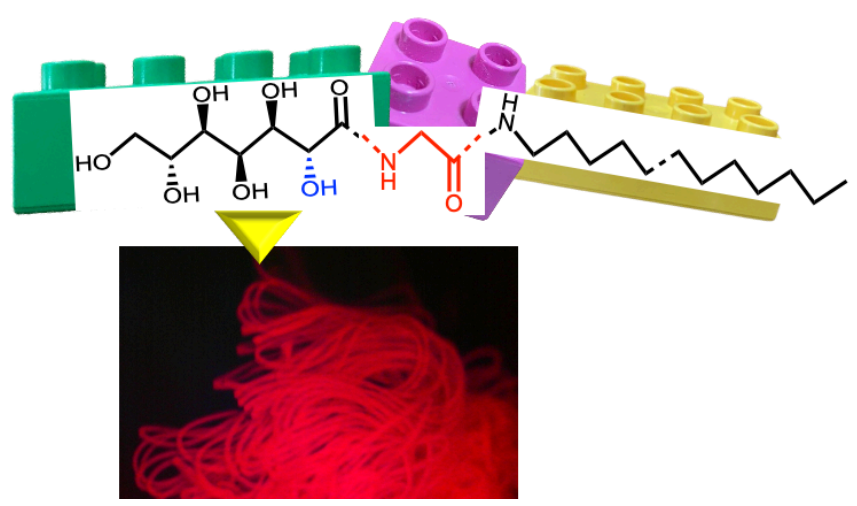

\section{Abstract}

\section{Hypothesis}

Recently, a low molecular weight hydrogel based on a carbohydrate alkyl amide has been successfully used as biomaterial for neuron cell culture and for 3D printing. Varying the molecular structure should make it possible to extend the library of carbohydrate low molecular weight hydrogels available for these applications and to improve their performances.

\section{Experiments}

Thirteen molecules easy to synthetize and designed to be potentially biocompatible were prepared. They are based on gluconamide, glucoheptonamide, galactonamide, glucamide, aliphatic chains and glycine. Their gelation in water was investigated in thermal conditions and wet spinning conditions, namely by dimethylsulfoxide-water exchange under injection.

\section{Findings}

Nine molecules give hydrogels in thermal conditions. By wet spinning, six molecules selfassemble fast enough, within few seconds, to form continous hydrogel filaments. Therefore, the method enables to shape by injection these mechanically fragile hydrogels, notably in the perspective of 3D printing. Depending on the molecular structure, persistent or soluble gel filaments are obtained. The microstructures are varied, featuring entangled ribbons, platelets or particles. In thermal gelation, molecules with a symmetrical polar head (galacto, glucoheptono) give flat ribbons and molecules with an asymmetrical polar head (gluco) give helical ribbons. The introduction of an extra glycine linker disturbs this trend.

keywords: molecular gel, supramolecular, LMWG, self-assembly, saccharide, aldonamide, wet spinning, injectable

\section{Introduction}

"Low molecular weight gels" (LMWG) or "molecular gels" form a class of gels with specific properties that differentiate them from polymer hydrogels. They result from the self-assembly of small molecules into fibers or other kind of aggregates that eventually entraps a large amount of an organic solvent (organogels) ${ }^{1}, 2$ or water (hydrogels) $)^{3,4,5,6,7,8,9}$. The chemical structure is 
perfectly defined (no polydispersity) and a variety of self-assembled micro/nanometric objects are formed depending on the structure of the gelator (helices, grooves, ribbons, flakes, etc, of different sizes). This well-defined micro/nanostructuration is less often observed in polymer gels. More specifically when biocompatible molecular hydrogels are used as scaffolds for cell culture $^{10,11,12,13}$ what cells feel at the micro or nanometric scale will depend on the micro/nanostructuration, that is different from one gel to another. They can sense the stiffness but also the topography at the nano and microscale ${ }^{14,15,16}$, and even the chirality of the selfassembled fibers ${ }^{17}$. Intracellular uptake can also occur and changes the cell fate ${ }^{14}$. In addition, in some conditions, the self-assembly can be very well controlled, to get, for example, aligned fibers, that can serve as guide for cells or for other purposes.

Molecular hydrogels can have various molecular structure, often based on peptides ${ }^{11}, 5,{ }^{18},{ }^{19},{ }^{20},{ }^{21}, 22,{ }^{23},{ }^{24}$ nucleosides ${ }^{25},{ }^{26}$, aromatic molecules linked through amides, carbohydrates, ${ }^{9},{ }^{27},{ }^{28},{ }^{29},{ }^{30}$. Molecular hydrogels derived from carbohydrates are interesting because it is possible to have access to a variety of hydroxyl stereochemistry and hydrogen bonding patterns that impact the shape of the self-assembled objects. They also are good candidates for making biocompatible hydrogels, provided that the molecular design also includes biocompatible linkers and adducts ${ }^{9}, 3$. From this point of view, they differ from peptide molecular gels also used as cell culture scaffolds ${ }^{18}$ by presenting essentially patterns with multiple hydroxyls in contact with the cells, rather than the characteristic groups of amino acids.

We have also shown in recent work that one of these molecules, N-heptyl-D-galactonamide can be wet-spun by a solvent-exchange process ${ }^{31}$. In this technique, gel filaments are obtained by injecting a solution of the gelator in dimethylsulfoxide (DMSO) into a water bath. Diffusion of water within the liquid jet of DMSO triggers the self-assembly of the gelator, the formation of the supramolecular assemblies and thus, the formation of a continuous highly hydrated gel filament. Inside the filament, the supramolecular fibers are organized radially, highlighting that the self-assembly has followed the water diffusion pattern. This phenomenon has been observed also for peptides self-assembled at an aqueous-aqueous interface ${ }^{32}$ and for wet spun polymers ${ }^{33}$. Therefore, this technique can give well-organized architectures at the microscopic level. It adds a new method in the toolbox for controlling precisely the self-assembly of supramolecular gels $^{32,34,35,36,37,38,39,40,41,42,43}$ and could be used as a template for mineralization or other kind of transformation.

The method has also been transposed to 3D printing, leading to the production of 3D printed fibrillar networks made of only small gellifying synthetic molecules and a high percentage of water ${ }^{44}$. 3D printed structures for cell culture made of only molecular gel, without any polymer are still scarce, because supramolecular hydrogels are very soft hydrogels that hardly sustain the weight of the upper layers. It is also because methods for very quick gelation ensuring a good resolution of the patterns are still lacking. However, some examples of 3D printing have been described with peptides or nucleosides derivatives, with various resolutions. They are based on solvent or aqueous solution exchange, thixotropy or electrostatic selfassembly ${ }^{19,25,45,20,21,22}$. Using the DMSO- $\mathrm{H}_{2} \mathrm{O}$ solvent exchange described here, gelation occurs very quickly and makes it possible to obtain quite thin patterns. $3 \mathrm{D}$ printing opens up new perspectives for these supramolecular gels and also offers a range of new types of inks for making biocompatible scaffolds.

In order to expand the library of molecules similar to N-heptyl-D-galactonamide and the application of the wet spinning and 3D printing method by DMSO-water exchange, we have prepared a series of readily accessible carbohydrate-based gelators. The molecules are obtained 
in 1 to 3 synthetic steps and purified by crystallization. The gels are formed either thermally (by cooling down a homogeneous solution of the gelator obtained by heating) or by wetspinning. The structure of the supramolecular fibers obtained was determined by electron microscopy (cryo-SEM) and by Small Angle X-Ray Scattering (SAXS) ${ }^{46}$. Studying the wet spinning of the molecular gels will give the conditions of extrusion rate and concentration in which the gelation occurs. When these conditions are correctly set and if the gellifying rate of the gelator is adequate under solvent exchange, a continuous gel filament is formed. In a similar way, in 3D printing, the adequation between the printing speed, the material delivery rate and the setting rate of the material are critical factors for getting precise patterns. Therefore, studying the parameters that influence the obtention of a gel under wet spinning conditions is a prerequisite for implementing this method in $3 \mathrm{D}$ printing. In this process, we also wanted to know if the radial organization of the fibers that has been observed previously with N-heptylD-galactonamide ${ }^{31}$ also occurs when other molecules are self-assembled in these conditions. The question is how far this phenomenon can be generalized to other carbohydrate molecular gels.

Results and discussion

\section{1- Molecules design}

A series of thirteen molecules based on D-glucoheptonolactone (molecules $\underline{\mathbf{1}}, \underline{\mathbf{2}}, \underline{\mathbf{3}}, \underline{\mathbf{1 8}}, \underline{\mathbf{1 9}}$ ), Dglucamine $(\underline{4}, \underline{\mathbf{5}}, \underline{\mathbf{8}}, \underline{\mathbf{9}})$, D-gluconolactone $(\underline{\mathbf{1 6}}, \underline{\mathbf{1 7}})$, D-galactonolactone $(\underline{\mathbf{1 4}}, \underline{\mathbf{1 5}})$ and an alkyl chain have been synthetized. Five of them, molecules $\underline{\mathbf{1}}$ to $\underline{\mathbf{3}}$ in Fig. 1 and $\underline{\mathbf{4}}, \underline{\mathbf{5}}$ in Fig. 2 are simple adducts between different sugar polar heads and alkyl chains of different length (hexyl, octyl, dodecyl), linked with an amide or a urea bond. Their structures differ from molecules already described in the litterature by Fuhrop et al. ${ }^{28},{ }^{12}$. For eight of them, a supplementary glycine group has been added between the sugar group and the alkyl chain, thus bringing flexibility and two amide bonds to promote self-assembly instead of only one (molecules $\underline{\mathbf{8}}$ and $\mathbf{9}$ in Fig. 2 and 14 to 19 in Fig. 3). In all cases, the design has been made with biocompatible building blocks and links in the perspective of using them as scaffolds for cell culture. Two gelators derived from D-glucamine with a glycine linker previously described by Ohsedo et al. ${ }^{27}$, were prepared as well ( $\underline{\mathbf{8}}$ and $\underline{\mathbf{9}}$, Fig. 2$)$ in order to compare their properties to the new ones. Full synthesis schemes, protocoles and purification by recrystallization of the thirteen molecules are described in see SI-1.

\section{2- Thermal gelation}

The thermal gelation of the molecules was first determined. The formation of macroscopically homogeneous gels or other kinds of colloidal suspensions was visually noted and then analyzed by Transmission Electron Microscopy and Small Angle X-Ray scattering (SAXS). Nine molecules that self-assemble in a dense population of long ribbons give gels $(\underline{\mathbf{1}}, \underline{\mathbf{3}}, \underline{\mathbf{4}}, \underline{\mathbf{5}}, \underline{\mathbf{8}}, \underline{\mathbf{9}}, \underline{\mathbf{1 6}}$, $\underline{\mathbf{1 7}}, \underline{\mathbf{1 8}})$. Four molecules do not self-assemble in long and high aspect ratio objects as the main population. As a result, they do not support the formation of gels $(\underline{\mathbf{2}}, \underline{\mathbf{1 4}}, \underline{\mathbf{1 5}}, \underline{\mathbf{1 9}})$. The results are summarized in Table 1 and in Figures 1-2-3 for each polar head.

A general observation that can be made about the self-assembled fibers is the fact that twisted or helical fibers are more often formed when the polyol head has a "gluco" configuration, that

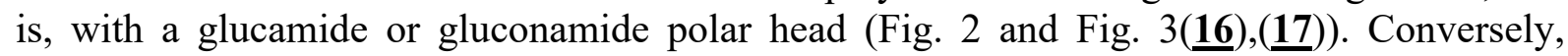
derivatives with a "glucoheptono" or a "galacto" configuration most often give self-assembled 
flat ribbons (Fig. 1, Fig. 3( $\underline{\mathbf{1 4}}), \underline{\mathbf{1 8}})$ and see ref $\left({ }^{28,12}\right)$ for N-alkyl-D-galactonamides, without a extra glycine linker, which form flat ribbons). Galacto and glucoheptono derivatives have polar heads where the four hydroxyl groups are arranged in a symmetrical pattern, which is not the case of the gluco series. The relationships between fiber morphology and the polyol configuration has been highlighted earlier by Fuhrop and coll. with a series of Nalkylaldonamides from hexoses ${ }^{28}$. Most often, 1-3-asymmetrical polyols ("gluco", "talo") form helical or twisted ribbons with short pitches, while symmetrical polyols ("galacto", "manno") give flat ribbons on the long range. Therefore, the same trend is observed in our series, adding one more example of with the glucohepto series, which behaves as a symmetrical aldonamide. When a glycine linker is added (molecules $\underline{\mathbf{8}}, \underline{\mathbf{9}}$ and $\underline{\mathbf{1 4}}$ to $\underline{\mathbf{1 9}}$ ) polymorphism of the selfassemblies often increases. Also, the trend observed in simpler molecules about the symmetry of the polar head seems to be "broken" and "reversed" to some extent in the galacto series or in the glucamide series. For 15 (but not for 14) ("galacto" head), twisted ribbons are observed instead of flat ribbons ( $\mathrm{ref}^{12}$ ) and conversely, in $\underline{\mathbf{8}}$ or $\underline{\mathbf{9}}$ (glucamide head), flat ribbons are observed instead of twisted or helical ones for $\underline{4}$. This observation may help to rationally design the gelators depending on the desired kind of self-assembled fibers.

\begin{tabular}{|c|c|c|c|c|}
\hline Molecule & $\mathrm{wt} \%$ & macroscopic aspect & main type of objects & $\begin{array}{c}\text { size of objects } \\
(\mathrm{nm})\end{array}$ \\
\hline $\begin{array}{l}\text { Glucoheptonamides } \\
\underline{\mathbf{1}} \text { Hexyl } \\
\underline{\mathbf{2}} \text { Octyl } \\
\underline{\mathbf{3}} \text { Dodecyl }\end{array}$ & $\begin{array}{l}3 \% ; 5 \% \\
3 \% ; 5 \% \\
2 \%\end{array}$ & $\begin{array}{l}\text { cohesive white gel } \\
\text { flowing white viscous } \\
\text { suspension } \\
\text { cohesive white gel }\end{array}$ & $\begin{array}{c}\text { rolled flat ribbons } \\
\text { platelets } \\
\text { flat sheets }\end{array}$ & $\begin{array}{c}190-310 \\
- \\
-\end{array}$ \\
\hline $\begin{array}{l}\text { Glucamides } \\
\underline{4} \text { Dodecanoyl- } \\
\underline{\mathbf{5}} \text { Dodecylamine-, urea }\end{array}$ & $3 \%$ & $\begin{array}{l}\text { cohesive glitter gel } \\
\text { cohesive white gel }\end{array}$ & $\begin{array}{l}\text { twisted and rolled ribbons } \\
\text { twisted ribbons } \\
\text { flat ribbons }\end{array}$ & $\begin{array}{c}55-270 \\
55-140 \\
140-600\end{array}$ \\
\hline $\begin{array}{l}\underline{\mathbf{8}} \text { Hexadecanoylglycine- } \\
\underline{\mathbf{9}} \text { Octadecanoylglycine- }\end{array}$ & $\begin{array}{l}1 \% \\
2 \%\end{array}$ & $\begin{array}{l}\text { cohesive white gel } \\
\text { cohesive white gel }\end{array}$ & $\begin{array}{l}\text { flat ribbons } \\
\text { flat ribbons }\end{array}$ & $\begin{array}{l}70-450 \\
90-380\end{array}$ \\
\hline $\begin{array}{l}\text { Alkylglycinamide } \\
\text { Galactonamides } \\
\underline{14} \text { Hexadecyl }\end{array}$ & $0,25 \%$ & opalescent solution & flat ribbons & $\begin{array}{c}200-1200 \\
(\text { main } \approx 450 \mathrm{~nm})\end{array}$ \\
\hline$\underline{15}$ Octadecyl & $0,25 \%$ & opalescent solution & $\begin{array}{l}\text { twisted ribbons } \\
\text { round objects }\end{array}$ & $\begin{array}{c}70-130 \\
230-1900\end{array}$ \\
\hline $\begin{array}{l}\text { Alkylglycinamide } \\
\text { Gluconamides } \\
\underline{16} \text { Hexadecyl } \\
\underline{17} \text { Octadecyl }\end{array}$ & $2 \% ; 3 \%$ & $\begin{array}{l}\text { heterogenous } \\
\text { white gel } \\
\text { nearly transparent gel, } \\
\text { slightly blue (also forms } \\
\text { gel in DMSO-d6) }\end{array}$ & $\begin{array}{l}\text { helical ribbons } \\
\text { helical ribbons }\end{array}$ & $\begin{array}{c}30 \text { (single helix) } \\
50 \text { (double helix) } \\
85 \text { (triple helix) } \\
110-260 \text { (tubes) } \\
35-80 \text { (thin helix) } \\
70-150 \text { (tubes) }\end{array}$ \\
\hline $\begin{array}{l}\text { Alkylglycinamide } \\
\text { Glucoheptonamides } \\
\underline{18} \text { Hexadecyl } \\
\underline{19} \text { Octadecyl }\end{array}$ & $\begin{array}{l}2 \% \\
0.5 \%\end{array}$ & $\begin{array}{l}\text { flowing weak } \\
\text { opalescent gel } \\
\text { viscous opalescent } \\
\text { solution }\end{array}$ & $\begin{array}{l}\text { flat ribbons } \\
\text { ill defined }\end{array}$ & $\begin{array}{c}90-250 \\
-\end{array}$ \\
\hline
\end{tabular}

Table 1. Conditions for the preparation of gels by thermal route. Macroscopic and microscopic observations. TEM images in relation with Table 1 are in Figures 1-2-3. $(\underline{\mathbf{1 4}}, \underline{15}, \underline{19}$ cannot be solubilized at higher concentration in water). 


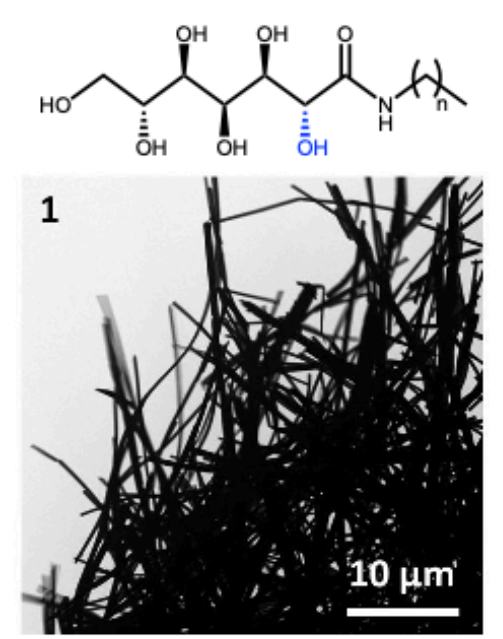

3

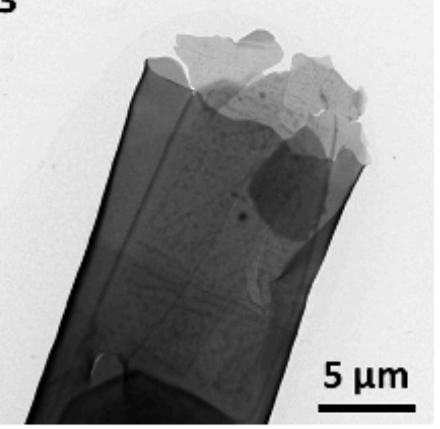

(1): $n=5 \quad N$-hexyl-D-glucoheptonamide

(2): $n=7 \quad N$-octyl-D-glucoheptonamide

(3): $\mathrm{n}=11 \mathrm{~N}$-dodecyl-D-glucoheptonamide
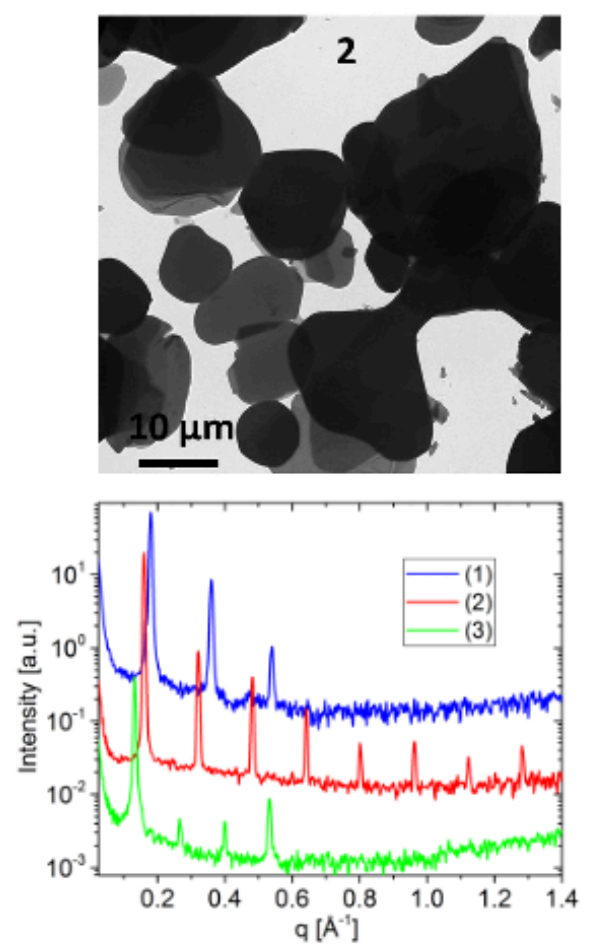

Figure 1: Molecular structure, transmission electronic microscopy and SAXS spectra of hydrogels based on glucoheptonamides derivatives (molecules $\underline{\mathbf{1}}-\underline{\mathbf{2}}-\underline{\mathbf{3}}$ )
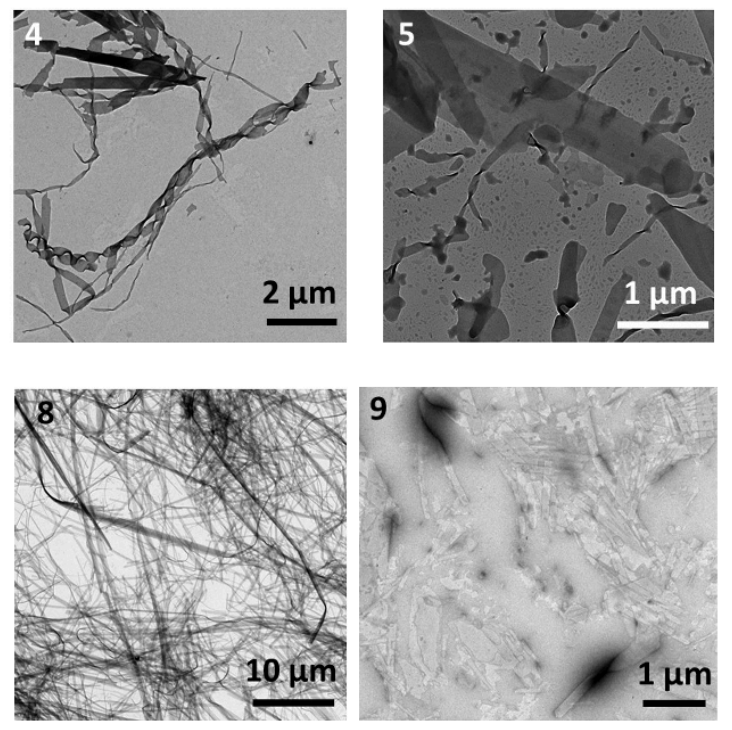<smiles>[Y6]C(=O)NC[C@H](O)[C@@H](O)[C@H](O)[C@H](O)CO</smiles>

(4): N-dodecanoyl-D-glucamine<smiles>C[14CH2]NC(=O)NC[C@H](O)[C@H](O)[C@H](O)[C@H](O)CO</smiles>

(5): N-dodecylamine-D-glucamine urea

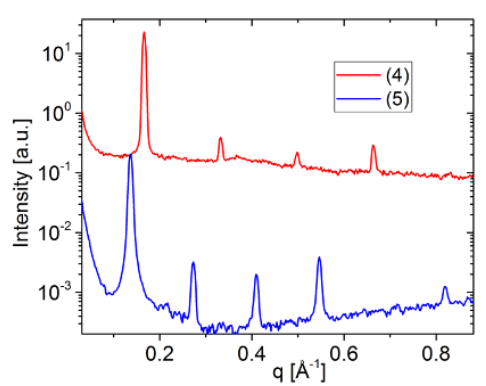

(8): $n=14 \quad \mathrm{~N}$-hexadecanoylglycine-D-glucamine

(9): $\mathrm{n}=16 \mathrm{~N}$-octadecanoylglycine-D-glucamine

Figure 2: Molecular structure, transmission electronic microscopy and SAXS spectra of hydrogels based on glucamide derivatives (molecules $\underline{4}-\underline{\mathbf{5}}-\underline{\mathbf{8}}-\underline{\mathbf{9}}$ ) 


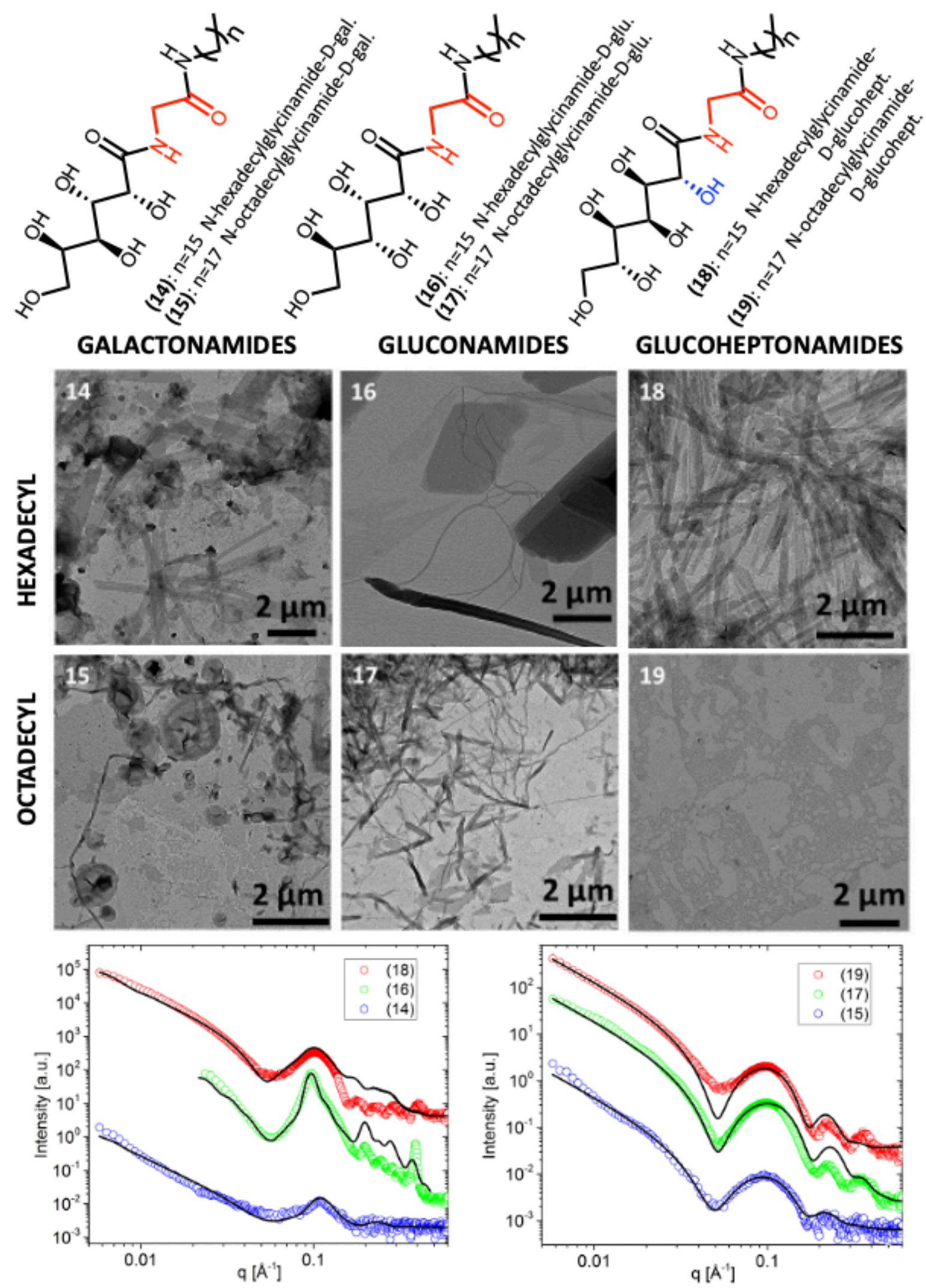

Figure 3: Molecular structure, transmission electronic microscopy and SAXS curves of hydrogels based on aldonamides derivatives with a glycine linker (molecules 14-15-16-17-1819). SAXS spectra black lines are fitting curves calculated according to methods described in SI-2. 
The arrangements of the gelators at the nanometric scale have been investigated by Small Angle $\mathrm{X}$-ray Scattering. Gelators without glycine linkers are characterized by a very ordered local structure indicated by intense peaks with connected relative positions (up to the $8^{\text {th }}$ order for Noctyl-glucoheptonamide $\underline{\mathbf{2}}$ ) ((Fig. 1 and $2, \underline{\mathbf{1}}$ to $\underline{\mathbf{5}}$ ). This is typical of a highly ordered lamellar arrangement of the molecules inside the assemblies. The measured characteristic repeating spacings reflects well the increase of the chain length and/or the sugar polar head (Table 2). The difference observed between measurements and a bilayer model with full extended chains can be ascribed to interdigitation and/or molecule bending. Interdigitation takes place when the chain length increases (e.g. glucoheptonamide derivatives $\underline{\mathbf{1}}$ and $\underline{\mathbf{2}}$ vs $\underline{\mathbf{3}}$ ). While the very large difference observed with glucamine derivatives may be rather attributed to bending (molecules $\underline{\mathbf{4}}, \underline{\mathbf{5}}$ ) or bending and interdigitation (molecules $\underline{\mathbf{8}}, \underline{\mathbf{9}}$ ). Since the $\mathrm{CH}_{2}$ group between the sugar and the $\mathrm{CO}$ group allows for more mobility, the molecule is more prone to take a kinked conformation. In SAXS spectra of gelators with glycine linkers, no or very small interaction peaks are present. Octadecyl chains do not show the presence of ordered structures (Fig. 3, SAXS spectrum (15-17-19)) and has been described using a model for non-interacting lyotropic lamellar phases randomly distributed (see SI-2). For hexadecyl derivatives $(\underline{\mathbf{1 4}}, \underline{\mathbf{1 6}}, \underline{\mathbf{1 8}})$, ordered bilayer arrangements and non-interacting lamellar structures have to be considered to describe the scattering data. The addition of a glycine linker between the sugar head and the aliphatic chain is clearly detrimental to the formation of long range ordered arrangements. The molecules are more flexible with a larger number of possible conformations allowing for hydrogen bond formation. As a result, these complex spectra must be attributed to the presence of different conformers with similar characteristic sizes which possibly induce arrangements with different degree of order and spacing. This fact is in accordance with findings in peptide hydrogels. The introduction of glycine increases the flexibility of the molecule and affects the peptide selfassembly and gelation ${ }^{24}$. In particular for $\underline{\mathbf{1 6}}$ and $\underline{\mathbf{1 8}}$, two different conformers could for example justify the high q peaks with different repeating spacings (Figure SI-2.2 and Table 2 and Table SI-2.2). All the values of lamellar spacing are in accordance with the sizes expected for these molecules considering the conformational variability and interdigitation. More details on the analysis of the molecular arrangements extracted from SAXS data and the models used are given in SI-2 and SI-5. 


\begin{tabular}{|c|c|c|c|}
\hline 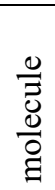 & $\begin{array}{l}\text { Bilayer size } \\
\text { of the } \\
\text { model } \\
(\AA)\end{array}$ & $\begin{array}{c}\text { Lamellar } \\
\text { spacing } \\
\text { SAXS } \\
(\AA)\end{array}$ & $\begin{array}{c}\text { Difference } \\
(\AA)\end{array}$ \\
\hline & \multicolumn{3}{|c|}{ Glucoheptonamides } \\
\hline 1 & 36.8 & 35.1 & 1.7 \\
\hline$\overline{2}$ & 40.8 & 39.1 & 1.7 \\
\hline$\overline{\mathbf{3}}$ & 52.4 & 47.1 & 5.3 \\
\hline & \multicolumn{3}{|c|}{ Glucamides } \\
\hline 4 & 48.4 & 37.8 & 10.6 \\
\hline$\underline{\mathbf{5}}$ & 53.2 & 46.3 & 6.9 \\
\hline$\underline{8}$ & 66.0 & $43.5(27)$ & 22.5 \\
\hline$\overline{9}$ & 71.0 & $52.5\left({ }^{27}\right)$ & 18.5 \\
\hline & \multicolumn{3}{|c|}{ Alkvlglycinamide Galactonamides } \\
\hline 14 & 65.8 & $56.8 \pm 8.0$ & $9.0 \pm 8.0$ \\
\hline$\underline{\overline{15}}$ & 70.8 & $65 \pm 3.5$ & $5.8 \pm 3.5$ \\
\hline \multirow{3}{*}{$\underline{16}$} & \multicolumn{3}{|c|}{ Alkylglycinamide Gluconamides } \\
\hline & 65.8 & $65 \pm 4$ & $0.4 \pm 4$ \\
\hline & & $54 \pm 3$ & $11.8 \pm 4.0$ \\
\hline$\underline{17}$ & 70.8 & $65 \pm 3.5$ & $0 \pm 3.5$ \\
\hline \multirow{3}{*}{$\underline{18}$} & \multicolumn{3}{|c|}{ Alkylglycinamide Glucoheptonamides } \\
\hline & 68.2 & $63 \pm 6.5$ & $5.2 \pm 6.5$ \\
\hline & & $58 \pm 6$ & $10.2 \pm 6$ \\
\hline$\underline{19}$ & 73.2 & $69.5 \pm 3.3$ & $3.7 \pm 3.3$ \\
\hline
\end{tabular}

Table 2: Bilayer sizes calculated from full extended non-interdigitated molecular models (Chemdraw, see SI-5), measured by SAXS and difference between the two.

SAXS measurements showed that all molecules self-assemble in bilayered structures possessing different degrees of order. The presence of different molecular conformations induces defects in the nanoscale arrangements and prevents long range order. Since SAXS probes the arrangement at the molecular level, no systematic relationship between the nanoscale lamellar order of the bilayers, the homogeneity in the morphology of self-assembled objects observed by TEM and the ability to form cohesive gels has been found. Nevertheless, a high order at the molecular level probed by SAXS tend to be a good indicator of the gelation ability, provided that high aspect ratio objects result from the self-assembly.

\section{3- Wet-spinning}

In order to develop a method for injecting the mechanically very fragile and non thixotropic sugar alkyl amides gels, wet spinning has been applied to the different molecules of the library. The principle is based on the injection of a solution of the gelator in DMSO into a water bath, with a blunt tip needle immersed in the bath. A liquid jet of DMSO-gelator is then formed. The diffusion of water into this liquid jet and the counter-diffusion of DMSO causes the molecule to self-assemble (Fig. 4a). If the concentration, the rate of extrusion, the shape of the selfassembled structures, their density and their entanglement and the rate of self-assembly under DMSO-water solvent exchange are suitable, the process results in the formation of a continuous filament of gel. The determination of the extrusion parameters, the gelation speed and gel behavior in wet spinning conditions are a prerequisite for using these gelators solutions as inks for 3D printing. For around half of the gelators studied, it was possible to find conditions to obtain continuous gel filaments and coils, by varying the concentration, the extrusion speed or the drop height of the DMSO jet in water. Several factors affect the formation of the gel 
filaments. The concentration must be high enough to sustain a continuous gel during the injection. It should not be too high to avoid the formation of clogs at the end of the nozzle. The molecule also must be soluble in DMSO at the chosen concentration. The extrusion rate also affects the obtention of a filament. If the extrusion rate is too high, the water diffusion is too slow to trigger the self-assembly and gelation during the fall: unshaped gel sets at the bottom of the tank. If the extrusion rate is too slow, a clog often forms at the end of the nozzle. Accordingly, the extrusion rate must be adapted between these two unsuitable conditions.

\begin{tabular}{|l|l|l|l|l|l|l|}
\hline Molecule & 2 & 3 & 4 & 5 & 16 & 18 \\
\hline $\mathrm{mg}$ in $1 \mathrm{~mL}$ DMSO & 50 & 5 & 50 & 25 & 25 & 25 \\
\hline $\mathrm{wt} \%$ in DMSO & 5 & 0.5 & 5 & 2.5 & 2.5 & 2.5 \\
\hline Flow rate $(\mu \mathrm{L} / \mathrm{min})$ & 20 & 20 & 50 & 100 & 20 & 20 \\
\hline
\end{tabular}

Table 3: conditions for wet spinning

From the library, six molecules out of thirteen (molecules $\underline{\mathbf{2}}, \underline{\mathbf{3}}, \underline{\mathbf{4}}, \underline{\mathbf{5}}, \underline{\mathbf{1 6}}, \underline{\mathbf{1 8}}$ ) formed gel filaments, in conditions detailed below and reported in Table 3 . Concentrations of gelators in DMSO are typically $0.5,2.5$ and $5 \mathrm{wt} \%$ and a $20 \mathrm{G}$ nozzle (ID: $0.91 \mathrm{~mm}$ ) has been used. For molecules $\underline{\mathbf{1}}, \underline{\mathbf{8}}, \underline{\mathbf{9}}, \underline{\mathbf{1 4}}, \underline{\mathbf{1 5}}, \underline{\mathbf{1 7}}, \underline{\mathbf{1 9}}$, no suitable conditions have been found. Some molecules are not soluble in DMSO at a sufficient concentration to give gel $(\underline{\mathbf{1 4}}, \underline{\mathbf{1 5}}, \underline{\mathbf{1 7}}, \underline{\mathbf{1 9}}, \underline{\mathbf{8}})$, one gelifies in

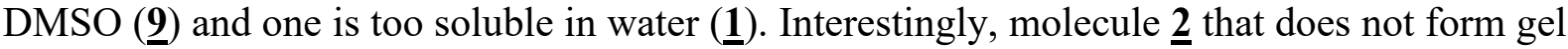
by thermal method, forms a cohesive gel filament by wet spinning. For most of the gelators, an extrusion rate of $20 \mu \mathrm{L} / \mathrm{min}$ is suitable, except for gelators $\underline{\mathbf{4}}$ and $\underline{\mathbf{5}}$ that tend to clog easily. For the latter, the extrusion rates must be increased to $50 \mu \mathrm{L} / \mathrm{min}$ and $100 \mu \mathrm{L} / \mathrm{min}$ respectively to give a gel filament. Depending on the structure of the gelators, complete gelation occurs early during the fall or later after deposition into a coil. With gelators $\underline{\mathbf{2}}$ (N-octyl-Dglucoheptonamide), $\underline{4}$ (N-dodecanoyl-D-glucamine) and $\underline{18}$ (N-hexadecylglycinamide-Dglucoheptonamide), the gel is very quickly formed during the $7 \mathrm{~cm}$ fall and appears white. With gelators $\underline{\mathbf{3}}$ (N-dodecyl-D-glucoheptonamide), $\underline{\mathbf{5}}$ (N-dodecylamine-glucamine urea) and $\underline{\mathbf{1 6}}(\mathrm{N}-$ hexadecylglycinamide-D-gluconamide), the gel forms a viscous transparent jet that coils before complete gelation (SI-3.1). This difference of setting rate should have an impact on the resolution in case of using the solutions as 3D printing inks. The filaments of $\underline{\mathbf{2}}, \underline{\mathbf{3}}$ and $\underline{\mathbf{4}}$ are dissolved a few days while filaments of $\underline{\mathbf{5}}, \underline{\mathbf{1 6}}$ and $\underline{\mathbf{1 8}}$ are not solubilized after several weeks. As a result, it will be possible to use $\underline{\mathbf{2}}, \underline{\mathbf{3}}, \underline{\mathbf{4}}$ as sacrificial gels, that will be easily removed by simple washing, while $\underline{\mathbf{5}}, \underline{\mathbf{1 6}}$ and $\underline{\mathbf{1 8}}$ can be used as more durable scaffolds. As a result, it will be possible to select the right gelator according to the expected usage.

The resulting filaments exhibit different macroscopic and microscopic aspects depending on the gelator. On a macroscopic scale, the filaments of $\underline{\mathbf{3}}, \underline{\mathbf{5}}, \underline{\mathbf{1 6}}$ and $\underline{\mathbf{1 8}}$ are flexible while those of $\underline{\mathbf{2}}$ and $\underline{4}$ are brittle (Fig. $4 \mathrm{~b}$ and SI-3.1, SI-3.2). Quite interestingly, the microscopic observations reveal that entangled fibers are not compulsory for making continuous and stable gel filament (Fig. 5). Instead, many other kinds of aggregation modes are observed depending on the compound: aggregated platelets, platelets organized like sand roses, aggregated particles or fibers. This difference of microscopic structure may relate to the mechanical properties of the filament (flexible or brittle). The microscopic morphology is much more homogeneous in gels obtained by wet spinning compared with gels obtained by thermal route showing that the wet spinning leads to a better control on the self-assembling process with this kind of gelators. 
In the present study, we also observed for molecule $\underline{\mathbf{5}}$ that the supramolecular fibers cleary have a radial organization (프, Fig. 5 and SI-4.1). Such an organization is not seen for the other gelators of this study. This phenomenon has been observed for the first time in our previous study dealing with the wet spinning of N-heptyl-D-galactonamide ${ }^{31}$. It thus appears that it is not generalizable. The formation of these radial patterns is in relation with the diffusion pattern of water within the DMSO jet. Depending on the properties of the two miscible fluids (notably viscosity), fingering patterns can be observed when the external fluid diffuses within the internal one ${ }^{47}$. Therefore, in addition to the self-assembly process specificities that will affect the kind of self-assembled aggregates (fibers, ribbons, platelets etc...), differences in the properties of the DMSO solutions (linked to the structure of the gelator, concentration) may affect this fingering process, explaining that a radial organization is observed for some gelators, but not for other ones ${ }^{47}$.

As the rate of solvent intermixing is a key parameter to trigger gelation, we have visualized this process by fluorescence. Solvatochromic fluorescent dyes are commonly used for this purpose exploiting the sharp changes in polarity, viscosity and hydrogen bonding that occurs upon moving from an organic (polar) solvent (in this study, DMSO) to water. Aggregation Induced Emission (AIE) $)^{48}$ have been selected since they are expected to turn fluorescent in the same of low molar fraction of DMSO as the gelator precipitates. Fluorescence is also expected to persist all along the wet spinning jet and in the filament, even long after its preparation. In the perspective of studying coaxial extrusions with two different gels, two readily accessible AIE dyes of different color have been selected: N-salicylaldehyde azine (green) ${ }^{49}$ and fluorenone salicylaldehyde azine (red) ${ }^{50}$ (see structure in SI-3.3). They have been added to the gelator solution in DMSO. The fluorescence intensity progressively increases from the nozzle to the coil, probing the increase of the water concentration inside the jet during the fall (Fig. 4c). In addition, at the beginning of the jet the center of the jet is dark, and the green or red shell progressively thicken from top to down, probing again the progressive diffusion of water during the fall (Fig 4c and SI-3.4).

Interstingly, the wet spinning with AIE still provide a well defined filament even if the solution contains the same weight of the gelator 3 and the AIE dye $(5 \mathrm{mg} / \mathrm{mL}$ each). It means that the the AIE did not impaired the formation of the gel filament. The latter is still made of only small molecules and water. This observation paves the way to the preparation of composites made only of small molecules or particles, without any polymer. 


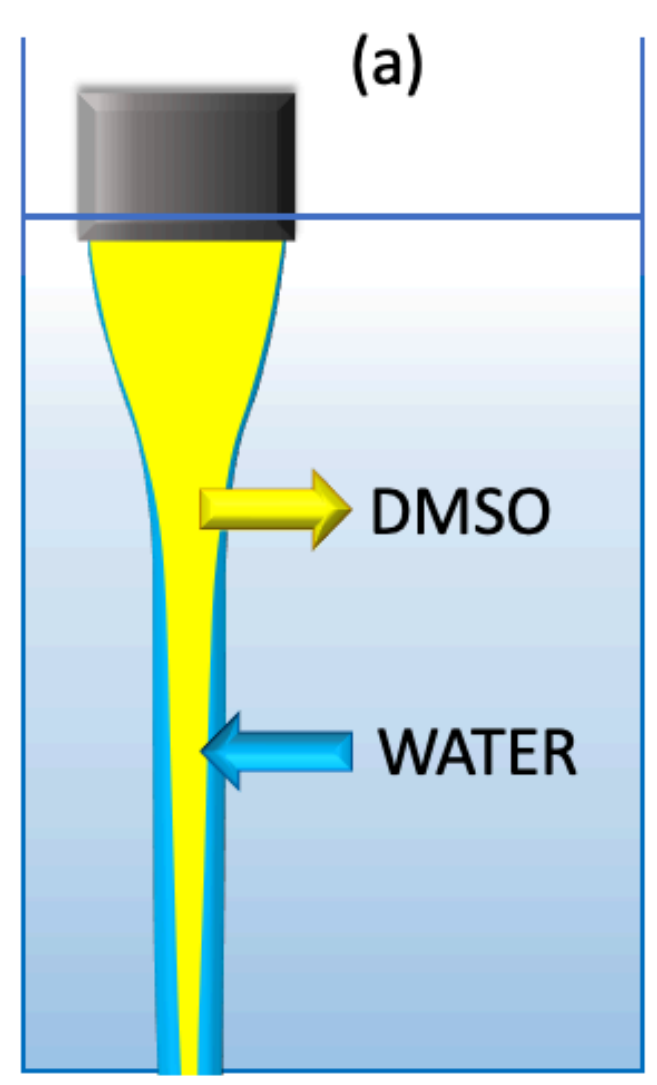

(b)
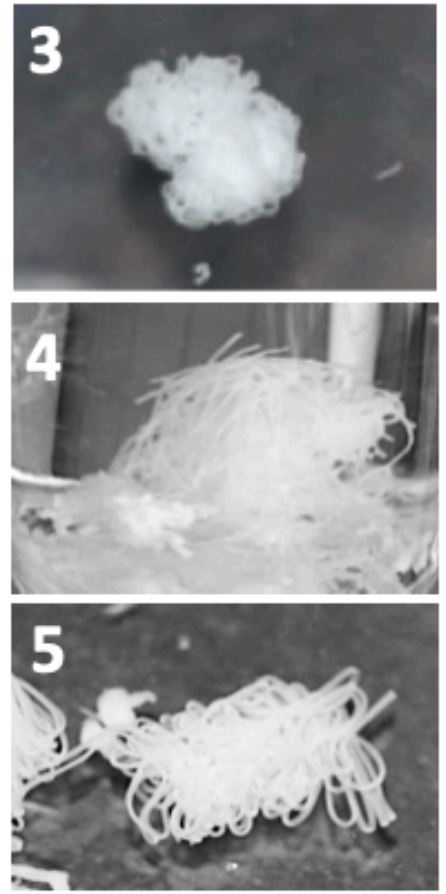

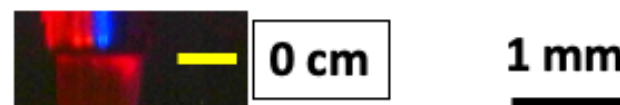

(c)
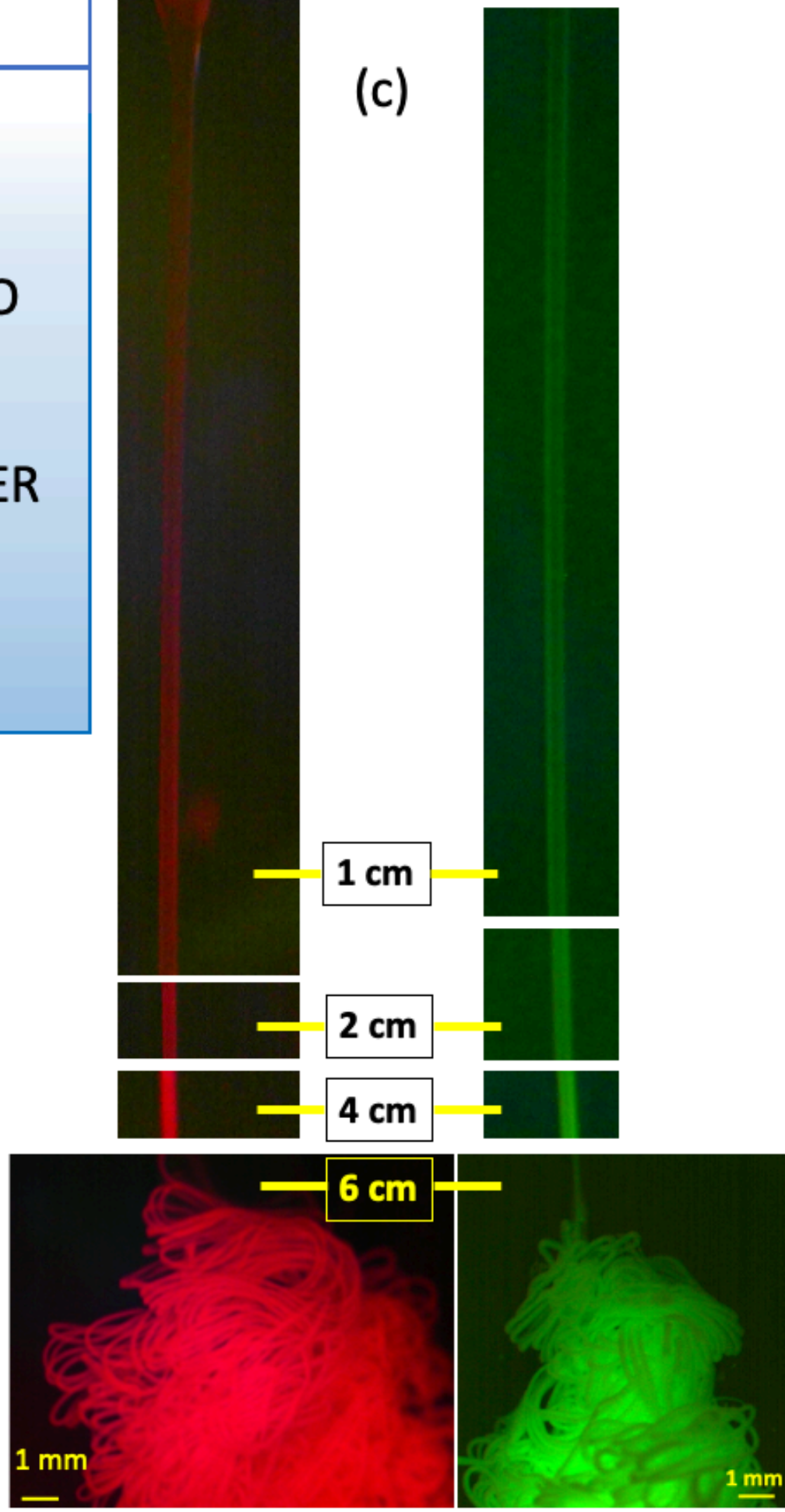

Figure 4: (a) Principle of the wet spinning and gelation by DMSO-water exchange under injection. (b) Macroscopic aspect of wet spun filaments of gels $\underline{\mathbf{3}} \underline{\mathbf{4}}$ and $\underline{\mathbf{5}}$ and resulting coils (see also SI 3.2). (c) Fluorescence monitoring of a jet of DMSO containing $5 \mathrm{mg} / \mathrm{mL}$ of $\mathrm{N}$ dodecyl-D-glucoheptonamide (compound 3 ) and $5 \mathrm{mg} / \mathrm{mL}$ of either (a) $N$-salicylaldehyde azine (green fluorescence) or (b) fluorenone salicylaldehyde azine (red fluorescence). The approximate distance to the nozzle exit is indicated in $\mathrm{cm}$. At the bottom, gel coil of fluorenone gel $\underline{\mathbf{3}}$ and salicylaldehyde azine. 

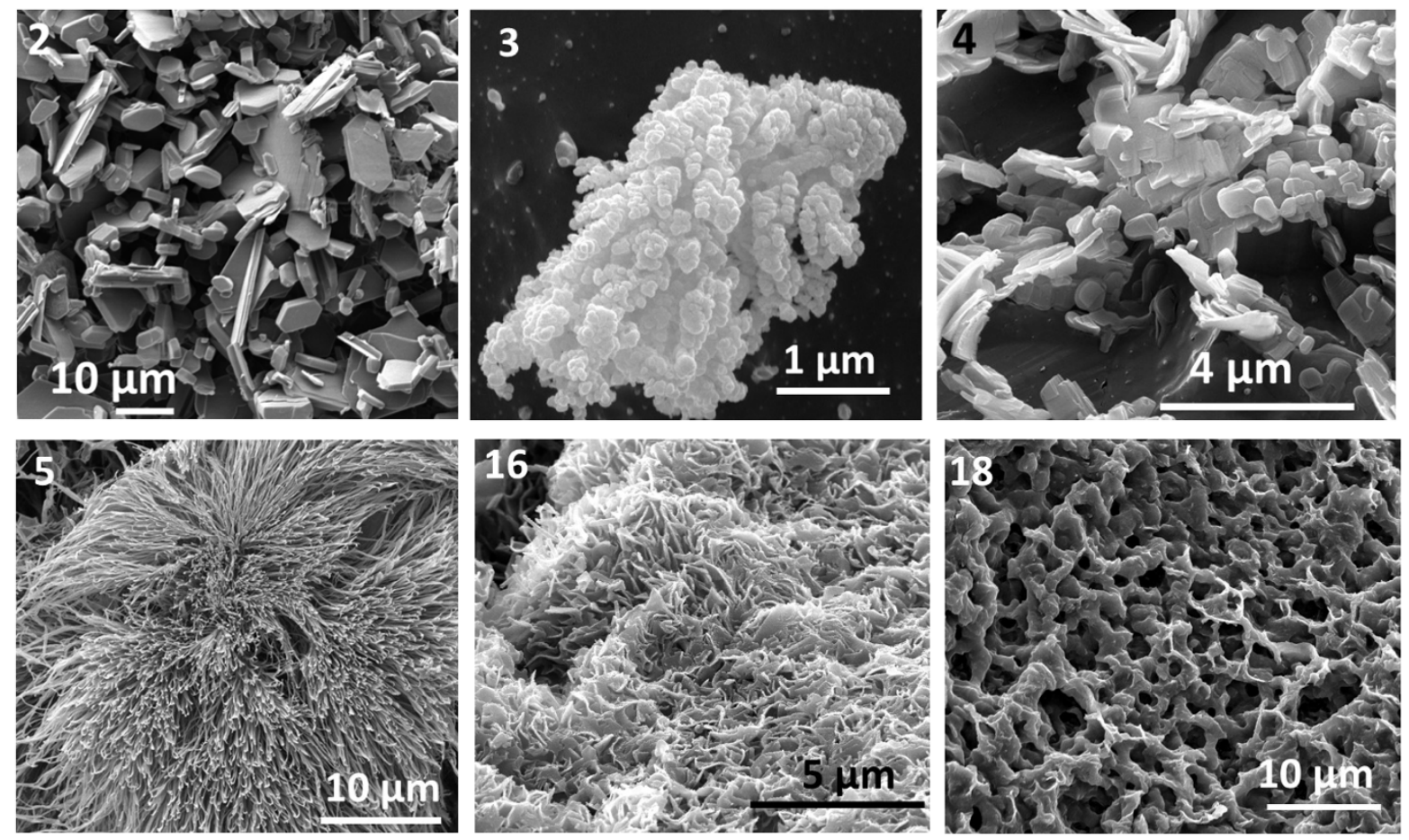

Figure 5: Cryo Scanning Electron Microscopy of the gels filaments (molecules $\underline{\mathbf{3}}, \underline{\mathbf{4}}, \underline{\mathbf{5}}, \underline{\mathbf{1 6}}, \underline{\mathbf{1 8}}$ ).

\section{5- Conclusion}

The possibility to wet spin low molecular weight hydrogels, which are hydrogels not based on polymers, was shown for the first time in 2019 with N-heptyl-D-galactonamide ${ }^{31}$. This technique is a unique way to make injectable this kind of hydrogels mechanically fragile, non thixotrope and to better control their self-assembly. The gel solution sets fast enough in these conditions to lead to the formation of a continous gel filament within few seconds. The study shows that it can be generalized to other molecules of this category. Six new molecules have

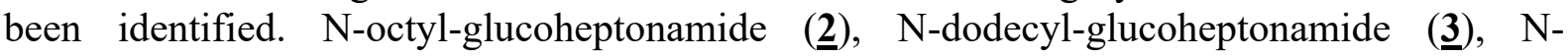
dodecanoyl-D-glucamine (4) give fast dissolving hydrogels that can be used as sacrificial inks while N-dodecylamine-glucamine urea (ㅁ), N-hexadecylglycinamide-D-gluconamide $(\underline{\mathbf{1 6}})$, Nhexadecylglycinamide-D-glucoheptonamide (18) give long lasting hydrogels. The latter have an improved stability compared with N-heptyl-D-galactonamide which was stable for two days only $^{31}$. Therefore, they can be used as persistent scaffolds. Their highly ordered lamellar structure may help the molecule to self-assemble very quickly in contact with water. Other low molecular weight hydrogels such as peptides or nucleosides currently developed for 3D printing are injected as viscous shear thinning solutions. This method is not possible with carbohydrate alkylamide hydrogel that are mechanically not reversible. In case of peptides or nucleosides, the gel setting after injection relies on thixotropy ${ }^{25,19}, \mathrm{pH}_{\text {exchange }} \mathrm{e}^{45}$, or $\mathrm{pH} /$ solvent exchange $^{45}$. All these processes are much slower compared with the quick setting occuring in the present study. They often result in large and not well resolved patterns. Given the instant gelation observed with the gelators of our study, better resolved architectures are expected in transposition to 3D printing, as it was observed with N-heptyl-D-galactonamide ${ }^{44}$. In the persepctive of biological applications, the carbohydrate molecular gels developed in this study could be an alternative to peptide hydrogels ${ }^{11,14},{ }^{19}$. They will bring other kinds of molecular bricks and microstructures in contact with the cells ${ }^{12}$. All these parameters are likely to have a different impact on the cell fate compared with peptides hydrogels and could be used on purpose. 


\section{Author contributions}

Conceptualization: JF, LM, PJ, CC; Data curation: DB, BL, PR, JF; Formal analysis: JF, BL, PR; Funding acquisition: JF, LM, PJ; Investigation: DB, AC, BL, PR, JF; Methodology: LM, PJ, AC, BL, PR, CC, JF; Project administration: JF; Resources: JF, CC; Supervision: JF; Validation: JF, DB, AC, BL, PR; Roles/Writing - original draft: JF, BL, DB, CC; Writing review \& editing: all authors.

\section{Acknowledgments}

We thank Federation FERMaT, Université de Toulouse, France - CPER IMATECBIO for SAXS analysis. The technical assistance provided by Catherine Claparols, Nathalie MartinsFroment (Mass spectrometry), Caroline Toppan, Pierre Lavedan (NMR) of the Institut de Chimie de Toulouse ICT-FR 2599 (Université de Toulouse, CNRS, Toulouse, France, https://ict.cnrs.fr) is gratefully acknowledged. Alexandre Wodrinski, Aurélie Chazot (IMRCP) are acknowledged for technical assistance in sample analyses. Bruno Payré and Dominique Goudounèche (CMEAB, Toulouse) are acknowlegded for their assistance in the acquisition of electronic microscopy images. This work was supported by the French National Research Agency (D.B.'s contract and A.C.'s Ph.D. grant, ANR "Neuraxe", grant NANR-15-CE070007-01).

\section{Experimental part}

General: in NMR spectra $500 \mathrm{MHz}$, peaks have been assigned from 2D NMR homonuclear and heteronuclear coupling experiments (COSY, HSQC, HMBC). AIE dyes, N-salicylaldehyde azine (green) ${ }^{49}$ and fluorenone salicylaldehyde azine "FAS" (red) ${ }^{50}$ were prepared according to procedures already published.

\section{Small Angle X-ray Scattering}

Scattering measurements have been performed with a XEUSS 2.0 SAXS/WAXS laboratory beamline equipped with a $\mathrm{Cu}$ source $(\mathrm{E}=8 \mathrm{keV})$ and a pixel detector PILATUS3 $1 \mathrm{M}$ from Detrics. Measurements are made in air, at room temperature, with kapton windows. A sampleto-detector distances have been used: $0.387 \mathrm{~m}$ (beam size $0.8 \mathrm{~mm} * 0.8 \mathrm{~mm}$ ) allowing a q range between $0.022 \AA^{-1}$ and $1.5 \AA^{-1}$. When necessary, a longer distance of $1216.5 \mathrm{~mm}$ has been used so to extend the q range to $0.006 \AA^{-1}$. Gels have been prepared by the thermal method in sealed vials and then transferred inside glass capillaries. SAXS curves have been fitted using SASVIEW (http://www.sasview.org/)

\section{Synthesis and chemical characterization of the molecules: see SI-1}

\section{Gel preparation by thermal method}

For the most hydrophobic molecules that are poorly soluble in water, heating to $100{ }^{\circ} \mathrm{C}$ at atmospheric pressure is insufficient. Therefore, the suspensions are heated at $130^{\circ} \mathrm{C}$ in crimped vials on a heating plate equipped with heating blocks for 2 to 10 minutes depending on the molecule, up to complete solubilization. After complete solubilisation, the vial is removed from the heating block and placed at room temperature. Macroscopic aspect of the resulting material is noted and the vial is turned upside down to distinguish flowing colloidal suspensions and non-flowing ones. 


\section{Gel preparation by wet spinning}

Solutions of the gelators have been prepared in dimethylsulfoxide (DMSO, 99.5\%). The following concentrations have been prepared for compounds $\underline{\mathbf{2}}, \underline{\mathbf{3}}, \underline{\mathbf{4}}, \underline{\mathbf{5}}, \underline{\mathbf{1 6}}, \underline{\mathbf{1 8}}$ are reported in Table 3.

For compounds $\underline{\mathbf{1}}, \underline{\mathbf{8}}, \underline{\mathbf{9}}, \underline{\mathbf{1 4}}, \underline{\mathbf{1 5}}, \underline{\mathbf{1 7}}, \underline{\mathbf{1 9}}(0.5$ to $1 \mathrm{wt} \%)$, no gel filament forms by wet spinning, only fluffy precipitates. At higher concentration, they are not soluble in DMSO at room temperature.

$100 \mu \mathrm{L}$ is injected in a water bath (in a transparent polystyrene flask with flat edges) so that the needle end is below the water level. The distance between the nozzle tip and the bottom of the flask is $7 \mathrm{~cm}$ (height of fall). Needle gauge is $20 \mathrm{G}$ (ID: $0.91 \mathrm{~mm}$ ). The flow rate is set by a syringe pump placed vertically. Videos and photos of jet and gel filaments are recorded with a camera.

For the characterization of water diffusion inside the jet by fluorescence, $5 \mathrm{mg} / \mathrm{mL}$ of salicylaldehyde azide (green fluorescence) or $5 \mathrm{mg} / \mathrm{mL}$ of fluorenone salicylaldehyde azide (red fluorescence) is added to the solution of $5 \mathrm{mg} / \mathrm{mL}$ of gelator $\underline{\mathbf{3}}$ in DMSO. The fluorescence is recorded with a Dinolite camera AM4115T-GRFBY with an exposition time of 4s. Both green and red dyes are excited at $480 \mathrm{~nm}$ and fluorescence is filtered at $510 \mathrm{~nm}$.

\section{CryoSEM and TEM}

For cryo-SEM observations, a piece of the gel filament was placed on the cryo-SEM cane and frozen at $-220{ }^{\circ} \mathrm{C}$ in liquid nitrogen. The frozen sample was fractured at $-145^{\circ} \mathrm{C}$ under vacuum in a cryo-transfer system chamber (Quorum PP3000 T). The sublimation was performed at -95 ${ }^{\circ} \mathrm{C}$ for $60 \mathrm{~min}$. The sample was metalized with $\mathrm{Pd}$ for $60 \mathrm{~s}$ and introduced in the microscope. The temperature was kept at $-145{ }^{\circ} \mathrm{C}$. Images were recorded with an FEG FEI Quanta 250 microscope, at $5 \mathrm{kV}$ for the acceleration voltage. For TEM observations, a piece of gel filament was placed on a grid (carbon film on copper, 200 mesh) for 3 minutes, and then removed. The grids are observed without staining using a Hitachi HT7700 transmission electron microscope (TEM) operating at $80 \mathrm{kV}$. The widths of a sample of fibers were measured manually using ImageJ.

\section{References}

(1) Matthews, L.; Przybyłowicz, Ż.; Rogers, S. E.; Bartlett, P.; Johnson, A. J.; Sochon, R.; Briscoe, W. H. The Curious Case of SDS Self-Assembly in Glycerol: Formation of a Lamellar Gel. Journal of Colloid and Interface Science 2020, 572, 384-395. https://doi.org/10.1016/j.jcis.2020.03.102.

(2) Arokianathan, J. F.; Ramya, K. A.; Deshpande, A. P.; Leemarose, A.; Shanmugam, G. Supramolecular Organogel Based on Di-Fmoc Functionalized Unnatural Amino Acid: An Attempt to Develop a Correlation between Molecular Structure and Ambidextrous Gelation. Colloids and Surfaces A: Physicochemical and Engineering Aspects 2021, 618, 126430. https://doi.org/10.1016/j.colsurfa.2021.126430.

(3) Du, X.; Zhou, J.; Shi, J.; Xu, B. Supramolecular Hydrogelators and Hydrogels: From Soft Matter to Molecular Biomaterials. Chem. Rev. 2015, 115 (24), 13165-13307. https://doi.org/10.1021/acs.chemrev.5b00299.

(4) Zhang, J.; Hu, Y.; Li, Y. Supramolecular Gels. In Gel Chemistry: Interactions, Structures and Properties; Zhang, J., Hu, Y., Li, Y., Eds.; Lecture Notes in Chemistry; Springer: Singapore, 2018; pp 9-59. https://doi.org/10.1007/978-981-10-6881-2 2.

(5) Shao, T.; Falcone, N.; Kraatz, H.-B. Supramolecular Peptide Gels: Influencing 
Properties by Metal Ion Coordination and Their Wide-Ranging Applications. ACS Omega 2020, 5 (3), 1312-1317. https://doi.org/10.1021/acsomega.9b03939.

(6) Eelkema, R.; Pich, A. Pros and Cons: Supramolecular or Macromolecular: What Is Best for Functional Hydrogels with Advanced Properties? Advanced Materials 2020, 32 (20), 1906012. https://doi.org/10.1002/adma.201906012.

(7) Wu, H.; Zheng, J.; Kjøniksen, A.-L.; Wang, W.; Zhang, Y.; Ma, J. Metallogels: Availability, Applicability, and Advanceability. Advanced Materials 2019, 31 (12), 1806204. https://doi.org/10.1002/adma.201806204.

(8) Draper, E. R.; Adams, D. J. Low-Molecular-Weight Gels: The State of the Art. Chem 2017, 3 (3), 390-410. https://doi.org/10.1016/j.chempr.2017.07.012.

(9) Morris, J.; Bietsch, J.; Bashaw, K.; Wang, G. Recently Developed Carbohydrate Based Gelators and Their Applications. Gels 2021, 7 (1), 24. https://doi.org/10.3390/gels7010024.

(10) Okesola, B. O.; Wu, Y.; Derkus, B.; Gani, S.; Wu, D.; Knani, D.; Smith, D. K.; Adams, D. J.; Mata, A. Supramolecular Self-Assembly To Control Structural and Biological Properties of Multicomponent Hydrogels. Chem. Mater. 2019, 31 (19), 7883-7897. https://doi.org/10.1021/acs.chemmater.9b01882.

(11) Marchini, A.; Favoino, C.; Gelain, F. Multi-Functionalized Self-Assembling Peptides as Reproducible 3D Cell Culture Systems Enabling Differentiation and Survival of Various Human Neural Stem Cell Lines. Front. Neurosci. 2020, 14. https://doi.org/10.3389/fnins.2020.00413.

(12) Chalard, A.; Vaysse, L.; Joseph, P.; Malaquin, L.; Souleille, S.; Lonetti, B.; Sol, J.-C.; Loubinoux, I.; Fitremann, J. Simple Synthetic Molecular Hydrogels from Self-Assembling Alkylgalactonamides as Scaffold for 3D Neuronal Cell Growth. ACS Appl. Mater. Interfaces 2018, 10 (20), 17004-17017. https://doi.org/10.1021/acsami.8b01365.

(13) Bayram, K. K.; Fitremann, J.; Bayram, A.; Yılmaz, Z.; Mehmetbeyoğlu, E.; Özkul, Y.; Rassoulzadegan, M. Gene Expression of Mouse Hippocampal Stem Cells Grown in a Galactose-Derived Molecular Gel Compared to In Vivo and Neurospheres. Processes 2021, 9 (4), 716. https://doi.org/10.3390/pr9040716.

(14) Maruyama, T.; Restu, W. K. Intracellular Self-Assembly of Supramolecular Gelators to Selectively Kill Cells of Interest. Polymer Journal 2020, 52 (8), 883-889.

https://doi.org/10.1038/s41428-020-0335-8.

(15) Alakpa, E. V.; Jayawarna, V.; Lampel, A.; Burgess, K. V.; West, C. C.; Bakker, S. C. J.; Roy, S.; Javid, N.; Fleming, S.; Lamprou, D. A.; Yang, J.; Miller, A.; Urquhart, A. J.; Frederix, P. W. J. M.; Hunt, N. T.; Péault, B.; Ulijn, R. V.; Dalby, M. J. Tunable Supramolecular Hydrogels for Selection of Lineage-Guiding Metabolites in Stem Cell Cultures. Chem 2016, 1 (2), 298-319. https://doi.org/10.1016/j.chempr.2016.07.001.

(16) Godbe, J. M.; Freeman, R.; Burbulla, L. F.; Lewis, J.; Krainc, D.; Stupp, S. I. Gelator Length Precisely Tunes Supramolecular Hydrogel Stiffness and Neuronal Phenotype in 3D Culture. ACS Biomater. Sci. Eng. 2020, 6 (2), 1196-1207. https://doi.org/10.1021/acsbiomaterials.9b01585.

(17) Dou, X.; Mehwish, N.; Zhao, C.; Liu, J.; Xing, C.; Feng, C. Supramolecular Hydrogels with Tunable Chirality for Promising Biomedical Applications. Acc. Chem. Res. 2020, 53 (4), 852-862. https://doi.org/10.1021/acs.accounts.0c00012.

(18) Kim, B. J.; Yang, D.; Xu, B. Emerging Applications of Supramolecular Peptide Assemblies. TRECHEM 2020, 2 (1), 71-83. https://doi.org/10.1016/j.trechm.2019.09.004.

(19) Susapto, H. H.; Alhattab, D.; Abdelrahman, S.; Khan, Z.; Alshehri, S.; Kahin, K.; Ge, R.; Moretti, M.; Emwas, A.-H.; Hauser, C. A. E. Ultrashort Peptide Bioinks Support Automated Printing of Large-Scale Constructs Assuring Long-Term Survival of Printed Tissue Constructs. Nano Lett. 2021, 21 (7), 2719-2729. 
https://doi.org/10.1021/acs.nanolett.0c04426.

(20) Jian, H.; Wang, M.; Dong, Q.; Li, J.; Wang, A.; Li, X.; Ren, P.; Bai, S. Dipeptide SelfAssembled Hydrogels with Tunable Mechanical Properties and Degradability for 3D Bioprinting. ACS Appl. Mater. Interfaces 2019, 11 (50), 46419-46426. https://doi.org/10.1021/acsami.9b13905.

(21) Almohammed, S.; Alruwaili, M.; Reynaud, E. G.; Redmond, G.; Rice, J. H.; Rodriguez, B. J. 3D-Printed Peptide-Hydrogel Nanoparticle Composites for SurfaceEnhanced Raman Spectroscopy Sensing. ACS Appl. Nano Mater. 2019, 2 (8), 5029-5034. https://doi.org/10.1021/acsanm.9b00940.

(22) Raphael, B.; Khalil, T.; Workman, V. L.; Smith, A.; Brown, C. P.; Streuli, C.; Saiani, A.; Domingos, M. 3D Cell Bioprinting of Self-Assembling Peptide-Based Hydrogels. Materials Letters 2017, 190, 103-106. https://doi.org/10.1016/j.matlet.2016.12.127.

(23) Zhang, G.; Zhang, L.; Rao, H.; Wang, Y.; Li, Q.; Qi, W.; Yang, X.; Su, R.; He, Z. Role of Molecular Chirality and Solvents in Directing the Self-Assembly of Peptide into an Ultra-PH-Sensitive Hydrogel. Journal of Colloid and Interface Science 2020, 577, 388-396. https://doi.org/10.1016/j.jcis.2020.05.087.

(24) Ishida, A.; Watanabe, G.; Oshikawa, M.; Ajioka, I.; Muraoka, T. Glycine Substitution Effects on the Supramolecular Morphology and Rigidity of Cell-Adhesive Amphiphilic Peptides. Chemistry - A European Journal 2019, 25 (59), 13523-13530. https://doi.org/10.1002/chem.201902083.

(25) Dessane, B.; Smirani, R.; Bouguéon, G.; Kauss, T.; Ribot, E.; Devillard, R.; Barthélémy, P.; Naveau, A.; Crauste-Manciet, S. Nucleotide Lipid-Based Hydrogel as a New Biomaterial Ink for Biofabrication. Scientific Reports 2020, 10 (1), 2850. https://doi.org/10.1038/s41598-020-59632-w.

(26) Latxague, L.; Benizri, S.; Gaubert, A.; Tolchard, J.; Martinez, D.; Morvan, E.; Grélard, A.; Saad, A.; Habenstein, B.; Loquet, A.; Barthélémy, P. Bolaamphiphile-Based Supramolecular Gels with Drugs Eliciting Membrane Effects. Journal of Colloid and Interface Science 2021, 594, 857-863. https://doi.org/10.1016/j.jcis.2021.03.026.

(27) Ohsedo, Y.; Oono, M.; Saruhashi, K.; Watanabe, H. N-Alkylamido- -GlucamineBased Gelators for the Generation of Thixotropic Gels. RSC Adv. 2014, 4 (89), 48554-48558. https://doi.org/10.1039/C4RA08346F.

(28) Fuhrhop, J. Hinrich.; Schnieder, Peter.; Boekema, Egbert.; Helfrich, Wolfgang. Lipid Bilayer Fibers from Diastereomeric and Enantiomeric N-Octylaldonamides. J. Am. Chem. Soc. 1988, 110 (9), 2861-2867. https://doi.org/10.1021/ja00217a028.

(29) Bielejewski, M.; Łapiński, A.; Demchuk, O. Molecular Interactions in High Conductive Gel Electrolytes Based on Low Molecular Weight Gelator. Journal of Colloid and Interface Science 2017, 490, 279-286. https://doi.org/10.1016/j.jcis.2016.11.059.

(30) Rizzo, C.; Andrews, J. L.; Steed, J. W.; D’Anna, F. Carbohydrate-Supramolecular Gels: Adsorbents for Chromium(VI) Removal from Wastewater. Journal of Colloid and Interface Science 2019, 548, 184-196. https://doi.org/10.1016/j.jcis.2019.04.034.

(31) Chalard, A.; Joseph, P.; Souleille, S.; Lonetti, B.; Saffon-Merceron, N.; Loubinoux, I.; Vaysse, L.; Malaquin, L.; Fitremann, J. Wet Spinning and Radial Self-Assembly of a Carbohydrate Low Molecular Weight Gelator into Well Organized Hydrogel Filaments. Nanoscale 2019, 11 (32), 15043-15056. https://doi.org/10.1039/C9NR02727K.

(32) Capito, R. M.; Azevedo, H. S.; Velichko, Y. S.; Mata, A.; Stupp, S. I. Self-Assembly of Large and Small Molecules into Hierarchically Ordered Sacs and Membranes. Science 2008, 319 (5871), 1812-1816. https://doi.org/10.1126/science.1154586.

(33) Pinto, T. V.; Cardoso, N.; Costa, P.; Sousa, C. M.; Durães, N.; Silva, C.; Coelho, P. J.; Pereira, C.; Freire, C. Light Driven PVDF Fibers Based on Photochromic Nanosilica@naphthopyran Fabricated by Wet Spinning. Applied Surface Science 2019, 470, 
951-958. https://doi.org/10.1016/j.apsusc.2018.11.203.

(34) Piras, C. C.; Slavik, P.; Smith, D. K. Self-Assembling Supramolecular Hybrid Hydrogel Beads. Angewandte Chemie International Edition 2020, 59 (2), 853-859. https://doi.org/10.1002/anie.201911404.

(35) Draper, E. R.; Adams, D. J. Controlling the Assembly and Properties of LowMolecular-Weight Hydrogelators. Langmuir 2019, 35 (20), 6506-6521. https://doi.org/10.1021/acs.langmuir.9b00716.

(36) Chivers, P. R. A.; Smith, D. K. Shaping and Structuring Supramolecular Gels. Nature Reviews Materials 2019, 4 (7), 463-478. https://doi.org/10.1038/s41578-019-0111-6.

(37) Contreras-Montoya, R.; Bonhome-Espinosa, A. B.; Orte, A.; Miguel, D.; DelgadoLópez, J. M.; Duran, J. D. G.; Cuerva, J. M.; Lopez-Lopez, M. T.; Cienfuegos, L. Á. de. Iron Nanoparticles-Based Supramolecular Hydrogels to Originate Anisotropic Hybrid Materials with Enhanced Mechanical Strength. Mater. Chem. Front. 2018, 2 (4), 686-699. https://doi.org/10.1039/C7QM00573C.

(38) Wang, Y.; Oldenhof, S.; Versluis, F.; Shah, M.; Zhang, K.; Steijn, V. van; Guo, X.; Eelkema, R.; Esch, J. H. van. Controlled Fabrication of Micropatterned Supramolecular Gels by Directed Self-Assembly of Small Molecular Gelators. Small 2019, 15 (8), 1804154. https://doi.org/10.1002/smll.201804154.

(39) Spitzer, D.; Marichez, V.; Formon, G. J. M.; Besenius, P.; Hermans, T. M. SurfaceAssisted Self-Assembly of a Hydrogel by Proton Diffusion. Angewandte Chemie International Edition 2018, 57 (35), 11349-11353. https://doi.org/10.1002/anie.201806668. (40) Vigier-Carrière, C.; Boulmedais, F.; Schaaf, P.; Jierry, L. Surface-Assisted SelfAssembly Strategies Leading to Supramolecular Hydrogels. Angewandte Chemie International Edition 2018, 57 (6), 1448-1456. https://doi.org/10.1002/anie.201708629. (41) Fores, J. R.; Criado-Gonzalez, M.; Chaumont, A.; Carvalho, A.; Blanck, C.; Schmutz, M.; Boulmedais, F.; Schaaf, P.; Jierry, L. Autonomous Growth of a Spatially Localized Supramolecular Hydrogel with Autocatalytic Ability. Angewandte Chemie International Edition 2020, 59 (34), 14558-14563. https://doi.org/10.1002/anie.202005377.

(42) Chen, J.-Y.; Komeily-Nia, Z.; Fan, L.-P.; Li, Z.-Y.; Yuan, B.; Tang, B.; Li, J.-L. Manipulating the Fractal Fiber Network of a Molecular Gel with Surfactants. Journal of Colloid and Interface Science 2018, 526, 356-365. https://doi.org/10.1016/j.jcis.2018.05.007. (43) Sang, Y.; Liu, M. Nanoarchitectonics through Supramolecular Gelation: Formation and Switching of Diverse Nanostructures. Mol. Syst. Des. Eng. 2019, 4 (1), 11-28. https://doi.org/10.1039/C8ME00068A.

(44) Chalard, A.; Mauduit, M.; Souleille, S.; Joseph, P.; Malaquin, L.; Fitremann, J. 3D Printing of a Biocompatible Low Molecular Weight Supramolecular Hydrogel by Dimethylsulfoxide Water Solvent Exchange. Additive Manufacturing 2020, 33, 101162. https://doi.org/10.1016/j.addma.2020.101162.

(45) Nolan, M. C.; Fuentes Caparrós, A. M.; Dietrich, B.; Barrow, M.; Cross, E. R.; Bleuel, M.; King, S. M.; Adams, D. J. Optimising Low Molecular Weight Hydrogels for Automated 3D Printing. Soft Matter 2017, 13 (45), 8426-8432. https://doi.org/10.1039/C7SM01694H.

(46) Draper, E. R.; Dietrich, B.; McAulay, K.; Brasnett, C.; Abdizadeh, H.; Patmanidis, I.; Marrink, S. J.; Su, H.; Cui, H.; Schweins, R.; Seddon, A.; Adams, D. J. Using Small-Angle Scattering and Contrast Matching to Understand Molecular Packing in Low Molecular Weight Gels. Matter 2020, 2 (3), 764-778. https://doi.org/10.1016/j.matt.2019.12.028. (47) Bischofberger, I.; Ramachandran, R.; Nagel, S. R. Fingering versus Stability in the Limit of Zero Interfacial Tension. Nature Communications 2014, 5 (1), 5265. https://doi.org/10.1038/ncomms6265.

(48) Aggregation-Induced Emission Special Issue. Angew. Chem. Int. Ed. 2020.

(49) Tang, W.; Xiang, Y.; Tong, A. Salicylaldehyde Azines as Fluorophores of 
Aggregation-Induced Emission Enhancement Characteristics. J. Org. Chem. 2009, 74 (5), 2163-2166. https://doi.org/10.1021/jo802631m.

(50) Wang, Z.; Gui, C.; Zhao, E.; Wang, J.; Li, X.; Qin, A.; Zhao, Z.; Yu, Z.; Tang, B. Z. Specific Fluorescence Probes for Lipid Droplets Based on Simple AIEgens. ACS Appl. Mater. Interfaces 2016, 8. 